\title{
Molecular identification of Pentatrichomonas hominis in animals in central and western Thailand
}

\author{
Aongart Mahittikorn', Ruenruetai Udonsom', Khuanchai Koompapong', Rachatawan Chiabchalard', \\ Chantira Sutthikornchai ${ }^{1}$, Preeyaporn Monatrakul Sreepian ${ }^{2}$, Hirotake Mori ${ }^{3}$ and Supaluk Popruk ${ }^{1 *}$
}

\begin{abstract}
Background: Pentatrichomonas hominis inhabits the digestive tracts of several vertebrates, such as humans, monkeys, pigs, dogs, cats and rats. This protozoan was originally considered a commensal of the digestive tract but has subsequently been identified as a potential zoonotic parasite and a causative agent of diarrhoea. Molecular techniques are considered more sensitive and specific to detect $P$. hominis. This study aimed to determine the presence and genetic diversity of $P$. hominis in animals in Thailand. A total of 403 faecal samples were collected from 119 cats, 55 dogs, 73 goats, 35 monkeys, 55 cattle and 66 pigs, and the presence of $P$. hominis was determined using the nested polymerase chain reaction method. Sequence analysis of small-subunit ribosomal RNA genes was used to determine the genotype of the organism.
\end{abstract}

Results: Twenty-six samples $(26 / 403,6.45 \%)$ were positive for $P$. hominis. The highest prevalence was found in cats $(21 / 119 ; 17.65 \%)$, followed by cattle $(3 / 55 ; 5.45 \%)$ and dogs $(2 / 55 ; 3.64 \%)$. Seven out of 26 nucleotides demonstrated $100 \%$ sequence identity with existing sequences; additionally, 16 novel sequence patterns were identified. All nucleotide sequences of $P$. hominis-positive samples were shown in the same branch with the previously described $P$. hominis sequences found in humans, dogs and goat.

Conclusion: This is the first study on P. hominis infections in animals in Thailand. Our findings revealed that the prevalence of $P$. hominis was significantly higher in cats than in cattle and dogs. Cats were the main reservoir host; however, $P$. hominis can infect several kinds of animals. Therefore, the proper waste management of animals is necessary to reduce and prevent infection in the community.

Keywords: Pentatrichomonas hominis, Cats, Cattle, Dogs, Thailand

\section{Background}

Pentatrichomonas hominis, formerly known as Trichomonas hominis, is a flagellated protozoan that inhabits the intestinal tracts of humans and animals and was originally believed to be a commensal protozoan [1]. However, studies have indicated $P$. hominis as the causative

\footnotetext{
* Correspondence: supaluk.pop@mahidol.ac.th

'Department of Protozoology, Faculty of Tropical Medicine, Mahidol University, Ratchawithi Road, Ratchathewi, Bangkok 10400, Thailand Full list of author information is available at the end of the article
}

agent of diarrhoea in mammals [2-5] and gastrointestinal or pulmonary diseases in children and older people $[6,7]$. Therefore, the pathogenic potential of this protozoan cannot be ruled out. Infection with this organism is prevalent in dogs, cattle, pigs and monkeys in economically developing regions and industrialised countries [8]. Later studies detected the presence of $P$. hominis in goat [9], water buffalo [5] and farmed wildlife [3]. Little is known about the transmission routes, biology, life cycle, primary host and animal reservoirs of this protozoan

(c) The Author(s). 2021 Open Access This article is licensed under a Creative Commons Attribution 4.0 International License, which permits use, sharing, adaptation, distribution and reproduction in any medium or format, as long as you give appropriate credit to the original author(s) and the source, provide a link to the Creative Commons licence, and indicate if changes were made. The images or other third party material in this article are included in the article's Creative Commons licence, unless indicated otherwise in a credit line to the material. If material is not included in the article's Creative Commons licence and your intended use is not permitted by statutory regulation or exceeds the permitted use, you will need to obtain permission directly from the copyright holder. To view a copy of this licence, visit http://creativecommons.org/licenses/by/4.0/ The Creative Commons Public Domain Dedication waiver (http://creativecommons.org/publicdomain/zero/1.0/) applies to the data made available in this article, unless otherwise stated in a credit line to the data. 
[10]. Traditionally, diagnostic methods for the detection of $P$. hominis have relied on microscopic examinations of the stool, which should be conducted immediately; alternatively, the stool material should be immediately preserved in a suitable fixative to preserve the morphological characteristics of the protozoan. However, trophozoites of $P$. hominis can be difficult to differentiate from Tritrichomonas foetus because of similarities in their motility and form [11]. Therefore, several polymerase chain reaction (PCR) assays that are considered more sensitive and specific and are now recognised as definitive for the detection of $P$. hominis have been described in the literature $[3,8,12,13]$. The development of molecular detection tools and the increase in the awareness of the zoonotic potential and adaptation of this parasite to a new host have resulted in an increasing number of studies on $P$. hominis $[3,5,8,9,14-16]$. Although the potential significance of $P$. hominis as a mammalian pathogen has been recognised, epidemiological studies in humans and animals in Thailand and many other countries are currently lacking. To the best of our knowledge, no studies have been conducted on the prevalence of $P$. hominis in animals in Thailand so far. Detailed investigations including systematic surveys of trichomonads in humans and animals are required to improve our knowledge of the zoonotic origins of trichomonads. This study aimed to determine the prevalence and molecular characterisation of $P$. hominis in dogs, cats, goats, cattle, pigs and monkeys in Thailand to understand the risks and dynamics of infections in humans and animals.

\section{Results}

The overall prevalence of $P$. hominis in animals was $6.45 \%(26 / 403)$. The highest prevalence was observed in cats $(21 / 119 ; 17.65 \%)$, followed by cattle $(3 / 55 ; 5.45 \%)$ and dogs $(2 / 55 ; 3.64 \%)$. Abandoned cats in temples located in the Nakhon Nayok Province were found to be most infected. No P. hominis-positive samples were obtained from goats, monkeys and pigs in this study. Table 1 enlists the global prevalence, case reports, diagnostic method and geographical region of $P$. hominis infection in animals.

High similarities $(\geq 98 \%)$ between the 26 nucleotide sequences of the partial small-subunit ribosomal RNA (SSU rRNA) gene of $P$. hominis and the sequences deposited in GenBank were observed in the present study. Seven out of 26 nucleotide sequences showed 100\% identity to the existing sequences (MF991102 [6 out of 7] and MK177545 [1 out of 7]), all of which were from cats. Nineteen out of 26 nucleotide sequences presented with 16 novel sequence patterns (Table 2).

We conducted a phylogenetic analysis of 19 nucleotide sequences from the $P$. hominis-positive samples and compared them with the reference sequences in the
GenBank database, as shown in Fig. 1. All nucleotide sequences in the $P$. hominis-positive samples were located within the same branch as that reported in humans, dogs and goats (reference studies).

\section{Discussion}

Several clinical and epidemiological studies employ molecular methods for detecting $P$. hominis from faecal samples [7, 8, 13, 27, 30]. In the present study, nested PCR was used to identify $P$. hominis infections in animals in Thailand. Accordingly, the positive samples were sequenced to identify $P$. hominis SSU rRNA genes in a convenience population of faecal samples from cats, dogs, goats, pigs, cattle and monkeys. A high prevalence of $P$. hominis infections has been identified in these animals previously [10]. To the best of our knowledge, this is the first report of $P$. hominis infections in animals in Thailand.

The overall prevalence of $P$. hominis in animals in this study was $6.45 \%$. The prevalence of $P$. hominis depends on geographical areas, animal species and diagnostic methods. Clearly, the molecular method most widely used in the literature is specific and more sensitive in detecting $P$. hominis than any other method because neither requires viable trophozoites nor an expert microscopist. Given a similar method for detection, the prevalence varies among countries (Table 1). One of the main findings of this study was the high prevalence of this protozoan in cats $(17.65 \%)$-which was higher than those reported in the USA, Japan and Brazil [12, 18, 23, 24 ] - followed by cattle $(5.45 \%)$ and dogs $(3.64 \%)$. This may be due to the high density of cats within limited spaces (temples and refuges), which increases the chances of infection from faecal contamination. Additionally, the natural behaviour of grooming among cats supports the transmission of infection through physical contamination $[11,24]$. The prevalence of $P$. hominis in dogs in this study was lower than those reported in China, Japan, South Korea and Poland [8, 24, 26, 27]. However, similar to previous reports, $P$. hominis infections were dominant in cats and dogs in the present study [19, 22, 24, 31]. Younger age and abnormal (liquid or semiliquid) faeces have been linked to an increased risk of $P$. hominis infection in dogs $[19,22]$. However, previous studies have reported that $P$. hominis has the potential for diarrhoea in dogs, cats and humans $[1,11$, 26]. Clinical cases of $P$. hominis infection with chronic diarrhoea have been observed in many animals (Table 1). Unfortunately, although the present study did not record the characteristics of animal faeces, doing so would explain the association between $P$. hominis infection and faeces type better. Moreover, the cats, dogs and monkeys did not have real owners; thus, their precise ages remained unknown. 
Table 1 Prevalence of Pentatrichomonas hominis infection in animals according to the country of identification and the diagnostic method used per published records

\begin{tabular}{|c|c|c|c|c|c|}
\hline Country & Type of animal/source of sample & Detection method & $\begin{array}{l}\text { Positive samples } / \mathbf{n} \\
\text { (\%) }\end{array}$ & Case report & References \\
\hline \multirow[t]{7}{*}{ Thailand } & Cats from a temple in Nakhon Nayok Province & Nested PCR, sequencing & $16 / 79(20.25)$ & - & This study \\
\hline & Cats from a refuge in Kanchanaburi Province & & $5 / 40(12.5)$ & - & This study \\
\hline & Dogs from a refuge & & $2 / 55(3.64)$ & - & This study \\
\hline & Goats from farms & & 0/73 (0) & - & This study \\
\hline & Monkeys in a town & & 0/35 (0) & - & This study \\
\hline & Cattle from farms & & $3 / 55(5.45)$ & - & This study \\
\hline & Pigs from farms & & 0/66 (0) & - & This study \\
\hline Austria & $\begin{array}{l}\text { Necropsy, biopsy or organ samples from cats } \\
\text { with diarrhoea }\end{array}$ & In situ hybridisation & $1 / 102(0.98)$ & - & [17] \\
\hline \multirow[t]{2}{*}{ Brazil } & Cats with or without diarrhoea & Faecal culture; PCR & 3/77 (3.89) & - & [18] \\
\hline & Cats with chronic diarrhoea & $P C R$, sequencing & - & 2 & [11] \\
\hline \multirow[t]{18}{*}{ China } & Dogs from pet hospitals & $\begin{array}{l}\text { Microscopy } \\
\text { Single-tube nested PCR, sequencing }\end{array}$ & $\begin{array}{l}62 / 315(19.7) \\
99 / 315(31.4)\end{array}$ & - & [19] \\
\hline & Police dogs & Nested PCR, sequencing & 69/252 (27.38) & - & [8] \\
\hline & Puppy with diarrhoea & PCRs, sequencing & - & 1 & [2] \\
\hline & Goats from farms & Single-tube nested PCR, sequencing & 2/781 (0.3) & - & [9] \\
\hline & Monkeys from a wildlife park & Nested PCR, sequencing & $28 / 60(46.67)$ & - & [8] \\
\hline & Yellow cattle & Nested PCR, sequencing & $15 / 323(4.6)$ & - & [5] \\
\hline & Dairy cattle & & $36 / 526(6.8)$ & - & [5] \\
\hline & Water buffalo & & 1/106 (0.9) & - & [5] \\
\hline & Pigs from farms & Nested PCR, sequencing & 38/158 (24.05) & - & [16] \\
\hline & Pigs from farms & Nested PCR, sequencing & $39 / 500(7.8)$ & - & [20] \\
\hline & A pig with diarrhoea & PCRs, sequencing & - & 1 & [21] \\
\hline & Sheep from farms & Single-tube nested PCR, sequencing & 0/832 (0) & - & [9] \\
\hline & Minks from farms & Nested PCR, sequencing & 29/60 (48.33) & - & [3] \\
\hline & Sika deer from farms & & 26/130 (20) & - & [3] \\
\hline & Rex rabbits from farms & & $13 / 80(16.25)$ & - & [3] \\
\hline & Blue foxes from farms & & $27 / 60(45)$ & - & [3] \\
\hline & Silver foxes from farms & & $26 / 60(43.33)$ & - & [3] \\
\hline & Raccoon dogs from farms & & $32 / 60(53.33)$ & - & [3] \\
\hline France & Puppies from breeding kennels & $P C R$, sequencing & 34/215 (15.8) & - & [22] \\
\hline \multirow[t]{5}{*}{ Japan } & Cats from public animal shelters & Microscopy & 0/1079 (0) & - & [23] \\
\hline & Kittens in pet shops & Nested PCR, sequencing & 2/409 (0.5) & - & [24] \\
\hline & Puppies in pet shops & & $38 / 544(7)$ & & [24] \\
\hline & Dogs from public animal shelters & Microscopy & $1 / 906(0.11)$ & - & [23] \\
\hline & Marmosets & $P C R$, sequencing & $58 / 88(66)$ & - & [25] \\
\hline Korea & Puppy with diarrhoea & $P C R$, sequencing & - & 3 & [26] \\
\hline Poland & Dogs from kennels & Real-time PCR & $5 / 41(12.19)$ & - & [27] \\
\hline \multirow[t]{7}{*}{ United States } & Cats attending an international cat show & $P C R$, sequencing & $2 / 103(1.9 \%)$ & - & [12] \\
\hline & Kittens with diarrhoea & Microscopy, histology & - & 4 & [28] \\
\hline & Dogs with diarrhoea & $P C R$, sequencing & 13/14 (92.85) & - & [4] \\
\hline & Dogs from a laboratory animal resources facility & $P C R$, sequencing & 0/19 (0) & - & [29] \\
\hline & $\begin{array}{l}\text { Dog faeces submitted to a veterinary diagnostic } \\
\text { laboratory for parasitologic analysis }\end{array}$ & & $0 / 81(0)$ & - & [29] \\
\hline & Dogs with diarrhoea & & - & 4 & [29] \\
\hline & Preputial washing or scraping from bulls & $P C R$, sequencing & - & 4 & [15] \\
\hline
\end{tabular}


Table 2 Accession numbers of the representative positive samples used for phylogenetic reconstruction in this study

\begin{tabular}{lllll}
\hline Type of animal & No. & GenBank accession No. (type of patterns) & Sequence similarity (\%) & Similar GenBank reference sequence \\
\hline Cats & 9 & MW074255 (CTM5) & 99.30 & MK177545 \\
& 24 & MW074256 (CTM1) & 99.65 & MF991102 \\
& 25 & MW074257 (CTM6) & 99.65 & MK177545 \\
& 73 & MW074258 (CTM9) & 99.62 & MH997493 \\
& 11 & MW074259 (CTM1) & 99.65 & MK177545 \\
& 56 & MW074260 (CTM6) & 99.65 & MF991102 \\
& 64 & MW074261 (CTM2) & 99.65 & MH997493 \\
& 67 & MW074262 (CTM10) & MF991102 \\
& 70 & MW074263 (CTM3) & 99.25 & MK177545 \\
& 71 & MW074264 (CTM7) & 98.95 & MF991102 \\
& 75 & MW074265 (CTM1) & 98.90 & MF991102 \\
& 76 & MW074266 (CTM4) & 99.65 & KX136884 \\
& 79 & MW074267 (CTM11) & 99.30 & MK177545 \\
& 80 & MW074268 (CTM8) & 99.23 & MF991102 \\
Dogttle & 15 & MW074269 (DTM1) & 99.28 & MF991102 \\
& 38 & MW074270 (DTM2) & 97.80 & MF991102 \\
& 35 & MW074271 (CTM1) & 98.94 & MF991102 \\
& 75 & MW074272 (CTM2) & 99.52 & MK177545 \\
\hline
\end{tabular}

The transmission of $P$. hominis was believed to occur directly between hosts, likely through the faecal-oral route via the ingestion of trophozoites [11]. However, recent studies have shown that $P$. hominis can form a pseudocyst stage under unfavourable environmental conditions, thus allowing the parasite to survive for several days outside the environment of the host $[2,5,7,22]$. Consequently, the possibility of transmission via a pseudocyst cannot be ruled out. Further molecular epidemiological investigations including the age of the animals and the characteristics of the faeces are required to determine the risk of $P$. hominis to humans.

The prevalence of $P$. hominis in cattle in the present study was consistent with that reported by Li et al. (2020) [5]. As was observed in dogs $[19,22]$, the prevalence of $P$. hominis was significantly higher in cattle with abnormal faeces but was not different between pre-weaned calves, post-weaned calves, juveniles and adult cattle [5]. Based on our molecular detection and sequencing results, the several isolates obtained from cats, dogs and cattle were confirmed to be $P$. hominis-positive. These findings implied that cats, dogs and cattle could act as natural hosts of $P$. hominis, which are consistent with the results of previous studies [2, $5,24,27]$. P. hominis may be a potential organism for zoonotic transmission in people who are in close contact with infected animals or consume water contaminated with $P$. hominis [5, 7]. According to Kamaruddin et al. (2014) [30], close contact with animals may be the potential risk factor for $P$. hominis human infection.
Although recent reports have documented that $P$. hominis infection can occur in goats [9, 14, 30], pigs [20] and monkeys [8], no positive sample was obtained in the present study. Therefore, the risk of zoonotic transmission of $P$. hominis from goats, pigs and monkeys in central Thailand is considered minimal. Given the settings observed in the goat and pig farms, where the animals are in close proximity to each other, the spread of an infection, if present, would be fast. Intestinal trichomonads, including $P$. hominis, are shed into the environment at the trophozoite stage and can survive for several days in the faeces leading to environmental contamination [7, 22, 32].

Previous studies showed a high prevalence of $P$. hominis in pigs and monkeys in China $[8,16,20]$. However, the prevalence of $P$. hominis in goat was much lower in China, the Philippines and Indonesia [9, 14, 30]. These differences might be attributed to differences in the age of the animals, the immunity when the stool samples were collected, the geographical location and the detection methods used. In this study, two previously described (CCH4 [human] and AHG1 [goat]) and 16 novel types of $P$. hominis were detected in the animal samples. All known genotypes were found in the cat samples, implying that they were not host-specific. Phylogenetic analyses revealed that the 16 novel genotypes were clustered in the same branch with the human, goat and dog samples. 


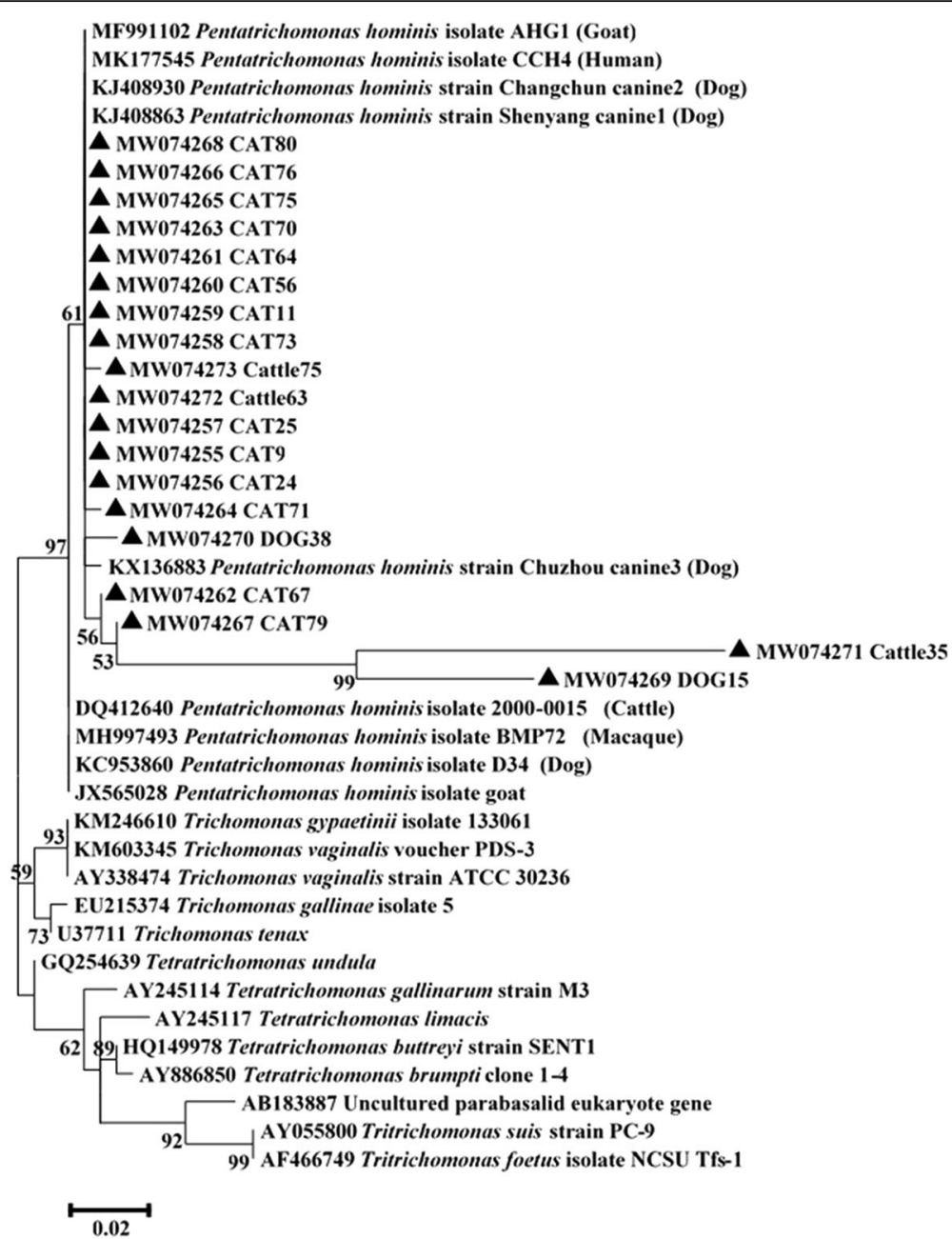

Fig. 1 Phylogenetic tree of $P$. hominis isolates and reference sequence of small-subunit ribosomal RNA (SSU rRNA) genes from GenBank (243 positions in the final dataset). Values on nodes represent bootstrap support from the maximum likelihood methods. $\mathbf{\Delta}$ Novel types identified in this study

In Thailand, apart from the data obtained from this study, little is known about the prevalence and genotype of $P$. hominis in humans and animals. Thus, additional epidemiological and genotyping studies of $P$. hominis are warranted.

\section{Conclusion}

The present study is the first to report the prevalence of $P$. hominis in animals in central and western Thailand by employing a molecular technique. $P$. hominis was highly prevalent in cats, followed by cattle and dogs indicating that cats may be the main natural host of $P$. hominis. Sixteen novel and two known genotypes were found in the animal samples, indicating that $P$. hominis may not be host-specific. We recommend the proper waste management of animals in the community, particularly in temples, refuges and farms to control $P$. hominis infections in restricted areas. As the first study to report the molecular epidemiological data on $P$. hominis infection among animals in Thailand, our study has some limitations. Firstly, given that it is a cross-sectional study, the findings can only be related to a certain time period. Secondly, samples were collected from different types of animals and different locations, and the sample size and species types were limited. Therefore, further studies with larger sample sizes (in each animal species), more animal species and wider survey sites are required to investigate the zoonotic potential of $P$. hominis.

\section{Methods}

Sample collection

A total of 403 stool samples were collected from 119 abandoned cats (79 from a temple in the Nakhon Nayok Province) (Central Thailand) and 40 samples from a 
refuge in the Kanchanaburi Province (Western Thailand), 55 abandoned dogs (from a refuge in the Nakhon Nayok Province), 73 goats (from farms in the Ayutthaya Province in Central Thailand), 35 monkeys (from a town in the Lopburi Province in Phra Prang San Yod), 55 cattle (from farms in the Ayutthaya Province) and 66 pigs (from farms in the Ayutthaya Province) between 2016 and 2020. The abandoned cats and dogs were fed by the Buddhist monks in a temple and caretakers in refuges.

The age of the cattle was $\geq 6$ months, whereas those of the goats and pigs were $4-12$ and $2-8$ months, respectively. The exact ages of the cats, dogs and monkeys were not known because they did not have real owners. All the animals were healthy and allowed to roam freely, except for the cats, goats and pigs, which were kept in big cages or pens. The stool samples were collected from the grounds immediately after defecation, stored in cool conditions during transportation and preserved at $20^{\circ} \mathrm{C}$ for DNA extraction.

The study protocol was approved by the Ethics Committee at the Faculty of Tropical Medicine-Animal Care and Use Committee, Mahidol University (FTM-ACUC 017/2020E).

\section{PCR amplification}

A fragment of the partial SSU rRNA genes from the extracted DNA was amplified using nested PCR. The PCR products were approximately 339 base pairs (bps) in length. The outer primer set was Ph1 ( $5^{\prime}$-ATGGCGAG TGGTGGAATA- $\left.3^{\prime}\right)$ and Ph2 (5'-CCCAACTACG CTAAGGATT-3') [8]. The inner primer set was Th3 (5'-TGTAAACGATGCCGACAGAG-3') and Th5 (5'CAACACTGAAGCCAATGCGAGC-3') [13]. Each $25 \mu \mathrm{L}$ reaction mixture contained $1 \times \mathrm{PCR}$ buffer, 1.5 $\mathrm{mM} \mathrm{MgCl} 2,0.2 \mathrm{mM}$ dNTPs, $1 \mu \mathrm{M}$ of each primer and $2.5 \mathrm{U}$ of Taq DNA polymerase (Fermentas, USA). The PCR cycling conditions of the primary round were as follows: initial denaturation at $94{ }^{\circ} \mathrm{C}$ for $5 \mathrm{~min}, 35$ cycles of denaturation at $95^{\circ} \mathrm{C}$ for $60 \mathrm{~s}$, annealing at $59^{\circ} \mathrm{C}$ for $60 \mathrm{~s}$ and extension at $72^{\circ} \mathrm{C}$ for $60 \mathrm{~s}$, followed by a final extension at $72{ }^{\circ} \mathrm{C}$ for $7 \mathrm{~min}$. The PCR cycling conditions for the second round were the same as those for the primary rounds, except for the annealing temperature $\left(61^{\circ} \mathrm{C}\right)$. The PCR products from the second round were $339 \mathrm{bps}$; they were separated on $2 \%$ agarose gel and visualised under a UV transilluminator.

\section{Sequencing and phylogenetic analysis}

All positive PCR products of the $339 \mathrm{bp}$ fragment from the $P$. hominis SSU rRNA gene obtained from the secondary PCR reaction were purified and sequenced in both directions using an ABI 3730xl automated DNA analyser (Basic Canada Inc., Ontario, Canada). The nucleotide sequences from all positive samples were tested by comparing the homology with those of the $P$. hominis sequences reported in the GenBank database, using a BLAST search of the National Center for Biotechnology Information database (https:/blast.ncbi.nlm.nih.gov/Blast.cgi). The representative nucleotide sequences of this study were deposited in GenBank under the following accession number MW074255-MW074273.

The nucleotide sequences of the $P$. hominis-positive samples and 25 reference sequences were manually edited using the BioEdit v.7.2.5 Software (Ibis Biosciences, Carlsbad, CA, USA), and multiple alignments were performed using ClustalW (Table 1). Finally, a phylogenetic analysis was conducted using the MEGA version 6 software (http://www.megasoftware.net). Evolution of the DNA sequences was best elucidated by the Jukes-Cantor model + gamma distribution. A phylogenetic tree was constructed using the maximum likelihood method and tested with 1000 bootstrap replicates.

\section{Statistical analysis}

Descriptive analyses (percentages) were used to describe the prevalence of $P$. hominis in the stool samples throughout the study regions.

\section{Abbreviations \\ bps: base pairs; PCR: Polymerase chain reaction; SSU rRNA: Small-subunit ribosomal RNA}

\section{Acknowledgements}

The authors would like to thank animal owners and the staff of Protozoology Department, Faculty of Tropical Medicine, Mahidol University.

\section{Authors' contributions}

AM, RU, KK, RC, CS, PMS, HM and SP conceived experiments. RU, KK, RC and CS prepared samples for laboratory experiments. AM and SP performed laboratory experiments. AM, PMS, HM and SP analysed and interpreted data. AM and SP wrote the manuscript. SP critically revised the manuscript. All authors contributed to, read and approved the final version of the manuscript.

\section{Funding}

This manuscript was supported by the Faculty of Tropical Medicine, Mahidol University, Thailand for English editing and article-processing charges, but did not have any additional roles in the data collection or analyses pertaining to this manuscript

\section{Availability of data and materials}

The datasets used and/or analysed during the present study are available from the corresponding author by reasonable request.

\section{Declarations}

Ethics approval and consent to participate For animal studies, ethical clearance was obtained from the Ethics Committee at the Faculty of Tropical Medicine-Animal Care and Use Committee, Mahidol University (FTM-ACUC 017/2020E). All methods were performed in accordance with relevant guidelines and regulations. Informed consent for sample collection was obtained from the animal owners.

Consent for publication

Not applicable. 


\section{Competing interests}

The authors declare that they have no competing interests.

\section{Author details}

'Department of Protozoology, Faculty of Tropical Medicine, Mahidol University, Ratchawithi Road, Ratchathewi, Bangkok 10400, Thailand. ${ }^{2}$ Faculty of Medical Technology, Rangsit University, Pathum Thani 1200, Thailand. ${ }^{3}$ Department of General Medicine, Faculty of Medicine, Juntendo University, Tokyo, Japan.

Received: 8 March 2021 Accepted: 12 May 2021

Published online: 02 June 2021

\section{References}

1. Zhang $\mathrm{N}$, Zhang H, Yu Y, Gong P, Li J, Li Z, et al. High prevalence of Pentatrichomonas hominis infection in gastrointestinal cancer patients. Parasit Vectors. 2019;12(1):423. https://doi.org/10.1186/s13071-019-3684-4.

2. Li WC, Gong PT, Ying M, Li JH, Yang J, Li H, et al. Pentatrichomonas hominis: first isolation from the feces of a dog with diarrhea in China. Parasitol Res. 2014;113(5):1795-801. https://doi.org/10.1007/s00436-014-3825-9.

3. Li X, Li J, Zhang X, Yang Z, Yang J, Gong P. Prevalence of Pentatrichomonas hominis infections in six farmed wildlife species in Jilin, China. Vet Parasitol. 2017;244:160-3. https://doi.org/10.1016/j.vetpar.2017.07.032

4. Tolbert MK, Leutenegger CM, Lobetti R, Birrell J, Gookin JL. Species identification of trichomonads and associated coinfections in dogs with diarrhea and suspected trichomonosis. Vet Parasitol. 2012;187(1-2):319-22. https://doi.org/10.1016/j.vetpar.2011.12.031.

5. Li W-C, J-m H. Fang Z, Ren Q, tang L, Kan Z-Z, et al. prevalence of Tetratrichomonas buttreyi and Pentatrichomonas hominis in yellow cattle, dairy cattle, and water buffalo in China. Parasitol Res. 2020;119(2):637-47. https://doi.org/10.1007/s00436-019-06550-0.

6. Dogan N, Tuzemen NU. Three Pentatrichomonas hominis cases presenting with gastrointestinal symptoms. Turkiye Parazitol Derg. 2018;42(2):168-70. https://doi.org/10.5152/tpd.2018.4846

7. Meloni D, Mantini C, Goustille J, Desoubeaux G, Maakaroun-Vermesse Z, Chandenier J, et al. Molecular identification of Pentatrichomonas hominis in two patients with gastrointestinal symptoms. J Clin Pathol. 2011;64(10):9335. https://doi.org/10.1136/jcp.2011.089326.

8. Li WC, Ying M, Gong PT, Li JH, Yang J, Li H, et al. Pentatrichomonas hominis: prevalence and molecular characterization in humans, dogs, and monkeys in northern China. Parasitol Res. 2016;115(2):569-74. https://doi.org/10.1007/ s00436-015-4773-8

9. Li WC, Wang K, Gu Y. Occurrence of Blastocystis sp and Pentatrichomonas hominis in sheep and goats in China. Parasit Vectors. 2018;11:93.

10. Maritz JM, Land KM, Carlton JM, Hirt RP. What is the importance of zoonotic trichomonads for human health? Trends Parasitol. 2014;30(7):333-41. https://doi.org/10.1016/j.pt.2014.05.005.

11. Bastos BF, Brener B, de Figueiredo MA, Leles D, Mendes-de-Almeida F. Pentatrichomonas hominis infection in two domestic cats with chronic diarrhea. JFMS Open Rep. 2018:4:2055116918774959.

12. Gookin JL, Stauffer SH, Levy MG. Identification of Pentatrichomonas hominis in feline fecal samples by polymerase chain reaction assay. Vet Parasitol. 2007;145(1-2):11-5. https://doi.org/10.1016/j.vetpar.2006.10.020.

13. Crucitti T, Abdellati S, Ross DA, Changalucha J, Dyck E, Buve A. Detection of Pentatrichomonas hominis DNA in biological specimens by PCR. Lett Appl Microbiol. 2004;38(6):510-6. https://doi.org/10.1111/j.1472-765X.2004.01528.x.

14. Dimasuay KG, Rivera WL. Molecular characterization of trichomonads isolated from animal hosts in the Philippines. Vet Parasitol. 2013;196(3-4): 289-95. https://doi.org/10.1016/j.vetpar.2013.03.019.

15. Dufernez F, Walker RL, Noel C, Caby S, Mantini C, Delgado-Viscogliosi P, et al. Morphological and molecular identification of non-Tritrichomonas foetus trichomonad protozoa from the bovine preputial cavity. J Eukaryot Microbiol. 2007:54(2):161-8. https://doi.org/10.1111/j.1550-7408.2007.00247.x.

16. Li W, Li W, Gong P, Zhang C, Yang J, Zhang X, et al. The prevalence of intestinal trichomonads in Chinese pigs. Vet Parasitol. 2015;211(1-2):12-5. https://doi.org/10.1016/j.vetpar.2015.04.028.

17. Mostegl MM, Wetscher A, Richter B, Nedorost N, Dinhopl N, Weissenbock H. Detection of Tritrichomonas foetus and Pentatrichomonas hominis in intestinal tissue specimens of cats by chromogenic in situ hybridization. Vet Parasitol. 2012;183(3-4):209-14. https://doi.org/10.1016/j.vetpar.2011.07.050.
18. Santos CS, Jesus VL, Mclntosh D, Berto BP, Lopes CW. Co-infection by Tritrichomonas foetus and Pentatrichomonas hominis in asymptomatic cats. Pesquisa Veterinária Brasileira. 2015;35(12):980-8. https://doi.org/10.1590/S01 00-736X2015001200007.

19. Li WC, Wang K, Zhang W, Wu J, Gu YF, Zhang XC. Prevalence and molecular characterization of intestinal Trichomonads in pet dogs in East China. Korean J Parasitol. 2016;54(6):703-10. https://doi.org/10.3347/kjp.2016.54.6.703.

20. Li WC, Wang K, Li Y, Zhao LP, Xiao Y, Gu YF. Survey and molecular characterization of Trichomonads in pigs in Anhui Province, East China, 2014. Iran J Parasitol. 2018;13(4):602-10.

21. Li W, Li W, Gong P, Meng Y, Li W, Zhang C, et al. Molecular and morphologic identification of Pentatrichomonas hominis in swine. Vet Parasitol. 2014:202(3-4):241-7. https://doi.org/10.1016/j.vetpar.2014.01.028.

22. Grellet A. Brunopolack, Feugier a, Boucraut-Baralon C, Grandjean D, Vandewynckel $L$, et al. prevalence, risk factors of infection and molecular characterization of trichomonads in puppies from French breeding kennels. Vet Parasitol. 2013;197(3-4):418-26. https://doi.org/10.1016/j.vetpar.2013.07.030.

23. Yamamoto N, Kon M, Saito T, Maeno N, Koyama M, Sunaoshi K, et al. Prevalence of intestinal canine and feline parasites in Saitama prefecture, Japan. Kansenshogaku Zasshi. 2009;83(3):223-8. https://doi.org/10.11150/ka nsenshogakuzasshi.83.223.

24. Itoh N, lijima Y, Ogura I, Yonekura N, Kameshima S, Kimura Y. Molecular prevalence of trichomonad species from pet shop puppies and kittens in Japan. Revista Brasileira de parasitologia veterinaria = Brazilian journal of veterinary parasitology : Orgao Oficial do Colegio Brasileiro de Parasitologia. Veterinaria. 2020:29:e014820.

25. Inoue T, Hayashimoto N, Yasuda M, Sasaki E, Itoh T. Pentatrichomonas hominis in laboratory-bred common marmosets. Exp Anim. 2015;64(4):3638. https://doi.org/10.1538/expanim.15-0010.

26. Kim YA, Kim HY, Cho SH, Cheun HI, Yu JR, Lee SE. PCR detection and molecular characterization of Pentatrichomonas hominis from feces of dogs with diarrhea in the Republic of Korea. Korean J Parasitol. 2010;48(1):9-13. https://doi.org/10.3347/kjp.2010.48.1.9.

27. Michalczyk M, Sokol R, Socha P. Detection of Pentatrichomonas hominis in dogs using real-time PCR. Pol J Vet Sci. 2015;18(4):775-8. https://doi.org/10.1 515/pjvs-2015-0100

28. Romatowski J. Pentatrichomonas hominis infection in four kittens. J Am Vet Med Assoc. 2000;216(8):1270-2. https://doi.org/10.2460/javma.2000.216.1270.

29. Gookin JL, Stauffer SH, Coccaro MR, Marcotte MJ, Levy MG. Optimization of a species-specific polymerase chain reaction assay for identification of Pentatrichomonas hominis in canine fecal specimens. Am J Vet Res. 2007; 68(7):783-7. https://doi.org/10.2460/ajvr.68.7.783.

30. Kamaruddin M, Tokoro M, Rahman MM, Arayama S, Hidayati AP, Syafruddin $D$, et al. Molecular characterization of various trichomonad species isolated from humans and related mammals in Indonesia. Korean J Parasitol. 2014; 52(5):471-8. https://doi.org/10.3347/kjp.2014.52.5.471.

31. Li W, Liu X, Gu Y, Liu J, Luo J. Prevalence of Cryptosporidium, Giardia, Blastocystis, and trichomonads in domestic cats in East China. J Vet Med Sci. 2019:19-0111.

32. Yao C, Köster LS. Tritrichomonas foetus infection, a cause of chronic diarrhea in the domestic cat. Vet Res. 2015;46(1):35. https://doi.org/10.1186/s13567015-0169-0

\section{Publisher's Note}

Springer Nature remains neutral with regard to jurisdictional claims in published maps and institutional affiliations.

Ready to submit your research? Choose BMC and benefit from

- fast, convenient online submission

- thorough peer review by experienced researchers in your field

- rapid publication on acceptance

- support for research data, including large and complex data types

- gold Open Access which fosters wider collaboration and increased citations

- maximum visibility for your research: over $100 \mathrm{M}$ website views per year

At BMC, research is always in progress.

Learn more biomedcentral.com/submission 